\title{
Direct anti-atherosclerotic therapy preventing intracellular cholesterol retention*
}

\author{
Alexander N. Orekhov ${ }^{1,2}$ \\ ${ }^{1}$ Institute for Atherosclerosis Research, Skolkovo Innovative Center, Moscow, Russia; a.h.opexob@gmail.com \\ ${ }^{2}$ Institute of General Pathology and Pathophysiology, Russian Academy of Medical Sciences, Moscow, Russia
}

Received 8 May 2013; revised 14 June 2013; accepted 2 July 2013

Copyright (C) 2013 Alexander N. Orekhov. This is an open access article distributed under the Creative Commons Attribution License, which permits unrestricted use, distribution, and reproduction in any medium, provided the original work is properly cited.

\section{ABSTRACT}

The key initiating process in atherogenesis is the subendothelial cholesterol retention, which is both necessary and sufficient to provoke lesion initiation. Retention of cholesterol transported by low density lipoprotien (LDL) in subendothelial cells of arterial wall, is an absolute requirement for lesion development. This allows us to consider intracellular cholesterol retention as a novel target for anti-atherosclerotic therapy. In this case, the target is not the level of blood cholesterol but the level of cholesterol in vascular cells. This review summarizes the results of our basic studies shedding light on the mechanisms of intracellular cholesterol retention. We describe our cellular models to search for antiatherosclerotic agents and demonstrate the use of these models for the development of antiatherosclerotic drugs. We use natural products as the basis of anti-atherosclerotic drugs because anti-atherosclerotic therapy should be long-term or even lifelong. Using cellular models and natural products, we have developed an approach to prevent intracellular cholesterol retention in cultured subendothelial aortic cells. We have developed drugs that reduce intracellular cholesterol retention, namely Allicor on the basis of garlic powder, anti-inflammatory drug Inflaminat (calendula, elder, and violet) possessing anti-cytokine activity and phytoestrogen-rich drug Karinat (garlic powder, extract of grape seeds, green tea leaves, hop cones, $\beta$-carotene, $\alpha$-tocopherol, and ascorbic acid). Treatment with Allicor or Inflaminat caused regression of carotid atherosclerosis in asymptomatic men. Karinat prevented the development of new atheroscle-

*Conflict of interest: the author confirms that this article presents no conflicts of interest. rotic plaques in postmenopausal women. Thus, the main findings of our basic research have been successfully translated into clinics. As a result, this translation, a novel approach to the development of anti-atherosclerotic therapy, has been established. Our clinical trials have confirmed the suitability of innovative approach and the efficacy of novel drugs developed on the basis our methodology.

Keywords: Allicor; Anti-Atherosclerotic Therapy; Atherosclerosis; Cell Culture; Drugs; Imaging; Intracellular Cholesterol Retention; Natural Products

\section{INTRODUCTION}

Eighteen years ago, Williams and Tabas [1,2] proposed the so-called the Response-to-Retention model of atherogenesis. Although atherosclerosis is a complex and multifactorial process, the key initiating process in atherogenesis is the subendothelial cholesterol retention which is both necessary and sufficient to provoke lesion initiation. Retention of cholesterol, transported by low density lipoprotien (LDL) in subendothelial space of arterial wall, is an absolute requirement for lesion development. According to Tabas et al. [3], the molecular basis of lipoprotein retention is associated with interaction of lipoprotein and extracellular matrix molecules. Local responses to these retained lipoproteins include inflammatory response with subsequent lesion development [4]. Specific focus is placed on the potential of these innate immune targets for therapeutic interventions to retard the progression of atherosclerosis or to induce its regression $[4,5]$. The response-to-retention model considers only the retention of cholesterol on extracellular matrix, completely ignoring the retention of intracellular cholesterol.

Retention of intracellular cholesterol in the arterial cells is the most prominent manifestation of atheroscle- 
rosis at the arterial cell level. This intracellular cholesterol retention is accompanied by increased proliferative activity of vascular cells and increased synthesis of extracellular matrix [6,7]. Along with the retention of intracellular cholesterol, proliferation and fibrosis are characteristic features of atherosclerosis at the arterial cell level too. Thus intracellular cholesterol retention may be an initial event of all major manifestations of atherosclerosis on cellular level. Intracellular cholesterol retention may be regarded as a novel target for antiatherosclerotic therapy.

This review summarizes the results of basic studies shedding light on the mechanisms of intracellular retention of cholesterol. We describe our cellular models to search for anti-atherosclerotic agents and demonstrate the use of these models for the development of antiatherosclerotic drugs. Finally, we report the successful translation of innovative attempts and novel drugs into clinical practice.

\section{BASIC STUDIES}

Intracellular retention of cholesterol is induced by LDL. It is well known that native lipoprotein usually does not increase the cholesterol content of the cell, however the incubation of cultured cells with chemically modified LDL results in a massive accumulation of cholesterol in the cells [8]. Thus, modified, but not native, LDL is the source of cholesterol retention in arterial cells. Cells populating atherosclerotic lesions are often overloaded with lipids, and their cytoplasms are almost completely filled with lipid inclusions [9]. These cells are referred to as foam cells because of foamy appearance of their cytoplasm.

In the blood of patients with coronary and extracoronary atherosclerosis we have discovered modified (desialylated) LDL [10-13]. This naturally occurring modified LDL induces cholesterol retention in cultured arterial cells [10-13]. Circulating modified LDL is multiple modified lipoprotein characterizing by lower sialic acid, triglyceride and cholesterol contents; smaller particle size; greater density and negative charge; higher aggregative activity; and some other specific features [14]. We have discovered an enzyme, trans-sialydase, that is responsible for the desialylation of LDL particles in the blood [15].

In addition to desialylated LDL, more electronegative LDL and small dense LDL have been found in human blood [16,17]. In cooperation with researchers who found more electronegative LDL and small dense LDL we carries out comparative studies and showed that the more electronegative LDL is desialylated LDL [18] as well as desialylated LDL isolated from patient blood [1013] is more electronegative. Desialylated LDL particle is smaller and denser than that of native LDL [19] as well as small dense LDL isolated from patients has a low content of sialic acid, i.e., it is desialylated [20].

Modified (desialylated) LDL stimulates anti-LDL auto-antibodies production [21-25]. Anti-LDL auto-antibodies and modified LDL form LDL-containing circulating immune complexes [26]. We have demonstrated LDL-containing circulating immune complexes and antiLDL auto-antibodies in the blood of atherosclerotic patients [26-28]. We have also found a positive correlation between the levels of LDL-containing immune complexes and the severity of atherosclerosis [26-30]. LDL is able to form complexes with collagen, elastin, and proteoglycans isolated from human aortic intima [31-36]. These LDL-containing complexes induce intracellular cholesterol retention as a result of increased uptake and decreased intracellular degradation of lipoproteins in complexes [35]. Naturally occurring multiple modified LDL has tendency to associate and forms self-associates, while native LDL does not associate [34]. We found a positive correlation between intracellular cholesterol retention caused by modified LDL and the degree of LDL self-association $[34,35]$. LDL-associates isolated by gel filtration were shown to induce a dramatic intra-cellular cholesterol retention. Thus, the formation of large LDL containing complexes (self-associates, immune complexes, and complexes with connective tissue matrix) is a necessary and sufficient condition for intra-cellular cholesterol retention.

Our knowledge of mechanisms of intracellular cholesterol retention allowed us to consider the prevention of intracellular cholesterol retention as a target for antiatherosclerotic therapy. As a model of intracellular cholesterol retention we use primary culture of subendothelial aortic cells and modified LDL or blood serum containing modified LDL. We use this model for the development of anti-atherosclerotic drugs.

\section{CELLULAR MODELS}

Cells are isolated from the subendothelial part of the human aortic intima between the endothelial lining and the media [36]. Using collagenase and elastase, viable cells are isolated from the subendothelial layer of the intima [37-39]. Isolated cells can be classified as the mixture of smooth muscle cells, pericyte-like cells, and macrophages [36-40]. The culture on which our experiments are performed is represented by this mixed population [36].

Cells isolated from atherosclerotic lesions retain all ma-jor characteristics of atherosclerotic cells when cultured. They are capable of synthesizing collagen, proteoglycans and other components of the extracellular matrix [6]. Cell cultured from fatty lesions have an enhanced proliferative activity [41], higher than that of cells cultured from unaffected intima [41,42]. Consider- 
able part of cells cultured from atherosclerotic lesions are foam cells, which contain numerous inclusions, likely lipid droplets, that fill the entirety of the cytoplasm [38]. Excess lipids in foam cells are mainly free cholesterol and cholesteryl esters [38]. It is important that the content and composition of lipids in cultured cells within the first 10-12 days in culture remain unchanged and correspond to the respective indices of freshly isolated cells $[38,42]$. Thus, our investigations are carried out directly on exactly those cells that require a therapeutic action in vivo.

To induce intracellular cholesterol retention we used blood sera obtained from coronary heart disease patients [43]. These sera contain modified LDL [8-11]. As a result serum is atherogenic, i.e. it is able to cause retention of intracellular cholesterol and stimulate other atherogenic manifestations in cultured cells [7,43-45]. Atherogenic serum was added to primary culture of subendothelial cells derived from an unaffected intima. Drug efficacy is judged by the ability to prevent the deposition of intracellular cholesterol in cultured cells. The prevention of intracellular cholesterol retention may be regarded as anti-atherosclerotic effect. In terms of arterial cells, any drug effect that does not directly prevent intracellular cholesterol retention is regarded as an indirect anti-atherosclerotic action. Only a drug that exhibits its preventive activity at the arterial level is a direct antiatherosclerotic drug. Using this model, we have examined the effects of different drugs and chemicals.

Using our cellular model we have tested three classes of cardiovascular drugs, calcium antagonists, beta-blockers and nitrates. These drugs are widely used in clinics in the therapy of various disorders that resulted from atherosclerosis of different arteries. The effect of several calcium antagonists on intracellular cholesterol retention was tested. Verapamil and nifedipine completely inhibited the accumulation of intracellular cholesterol induced by the sera, while other calcium antagonists, such as diltiazem, nicardipine, isradipine, and darodipine, substantially reduced cholesterol accumulation [46]. The examined calcium antagonists demonstrated anti-atherogenic action in vivo by inhibiting the development of experimental atherosclerosis in animals [47,48]. Thus, our in vitro data obtained using the cellular model correspond to the in vivo observations.

Nitrates and beta-blockers have been tested to examine their effect on atherosclerotic cellular indices. Nitrates only minimally affected cholesterol levels [49]. In contrast, all the examined beta-blockers, i.e., propranolol, alprenolol, metoprolol, pindolol, and timolol, increased intracellular cholesterol retention, i.e., all of these drugs exhibited pro-atherogenic activity in culture [46,49]. If beta-blockers have a similar effect in vivo, one may assume that these drugs are atherogenic and induce their atherogenic effects at the arterial cell level. Apparently, nitrates do not follow a similar trend.

Thus, three classes of cardiovascular drugs exert a different influence on intracellular cholesterol retention. Calcium antagonists exhibit anti-atherosclerotic actions. In contrast, beta-blockers are pro-atherogenic. Nitrates do not have an effect on intracellular cholesterol retention. Our data are consistent with the results of a clinical study reported by Loaldi et al. [50] who demonstrated that long-term oral administration of propranolol aggravates coronary atherosclerosis in patients with angina of effort compared with the calcium antagonists nifedipiene and isorobide dinitrate. Nifedipine showed the best effect on coronary atherosclerosis by suppressing the development of existing atherosclerotic lesions and preventing the appearance of new lesions. Isosorbide dinitrate was less effective. These clinical observations confirming our in vitro results encourage us to develop an anti-atherosclerotic therapy using our cellular model.

Naturally, the question arises whether the anti-atherosclerotic effects revealed in in vitro cellular model can be manifested in vivo. To answer this question, an ex vivo model was developed. In the ex vivo model, instead of agents, blood sera taken from patients after oral drug administration is added to cultured cells.

Two calcium antagonists, verapamil and nifedipin, and two beta-blockers, propranolol and pindolol, were examined using the ex vivo model [49,51]. Within $2-4$ hours after nifedipine or verapamil oral administration, the patients' sera was less atherogenic, i.e. induced less intracellular cholesterol retention. In contrast, the sera of patients who received propranolol or pindolol were proatherogenic. Its pro-atherogenic properties manifested themselves at the arterial cell level via the rise of intracellular cholesterol accumulation. This finding allows us to assume that not only in vitro, but also in vivo, calcium antagonists and beta-blockers are anti-atherosclerotic and pro-atherogenic drugs, respectively.

The effect of nifedipine on serum properties during a course has been assessed [46]. A patient received 20-mg doses of nifedipine three times a day at an 8-hour interval for 7 days. Twenty-eight days after regular nifedipine therapy, the atherogenicity of the patient's serum was considerably lower than at the beginning of the therapy. Directly after new dose of nifedipine, the intracellular cholesterol retention was notrevealed. In contrast, after a course treatment with the beta-blocker propranolol, the patient's serum acquired stable atherogenic properties. At the beginning of the course, the serum of this patient did not induce intracellular cholesterol retention; however, 28 days of regular propranolol therapy led to the emergence of atherogenicity, revealed even before the drug administration. 


\section{DRUG DEVELOPMENT}

Atherosclerosis develops over many years, so antiatherosclerotic therapy should be long-term or even lifelong. For such long-term anti-atherosclerotic therapy, conventional medicine will not work. Drugs developed on the basis of natural products can be a good alternative.

We have tested numerous extracts of natural products to reveal their effects on their capacity to prevent intracellular cholesterol retention caused by atherogenic blood sera from atherosclerotic patients. Naturally, the tested agents included anti-atherosclerotic, pro-atherogenic, and neutral products. Among the anti-atherosclerotic natural products, the most effective was garlic.

We investigated the in vitro effect of garlic extract on intracellular cholesterol retention. Garlic prevented the serum-induced accumulation of free cholesterol and reduced the accumulation of cholesteryl esters [52]. The effect of garlic on cholesteryl esters may be explained by the action on enzymes responsible for cholesteryl ester metabolism. We have shown that garlic inhibits acylCoA:cholesterol acyltransferase, which participates in cholesteryl ester formation, and stimulates cholesteryl ester hydrolase, which degrades cholesteryl esters [52].

Further investigations ex vivo confirmed the in vitro effects of garlic [53]. In ex vivo experiments we applied dry garlic powder. Using ex vivo model we optimized the effective dose of oral garlic powder administration. The anti-atherosclerotic activity of garlic powder was evaluated by the ability to reduce intracellular cholesterol retention. The dose-effect dependence was revealed by comparing the efficacy of the two doses, and we found that garlic powder possesses anti-atherosclerotic effects at a dose of $50-300 \mathrm{mg}$. The minimum dose causing maximum effect was $150 \mathrm{mg}$.

Using the optimal dose of $150 \mathrm{mg}$ garlic powder we have showed that long-term treatment for months and years leads to a significant reduction of intracellular cholesterol retention or its extinction $[53,54]$.

These data stimulated us to develop a drug based on garlic powder and carried out a clinical study of the effects of this drug on atherosclerosis regression.

\section{TRANSLATION INTO CLINICS}

We have developed the time-released garlic powder tablets referred to as Allicor that have been registered and are now being manufactured by INAT-Farma, Ltd. (Russia). The AMAR study (Atherosclerosis Monitoring and Atherogenicity Reduction) was carried out to estimate the effect of two-year treatment with Allicor on the progression of carotid atherosclerosis in asymptomatic men in a double-blinded, placebo-controlled randomized clinical trial (ClinicalTrials.gov Identifier, NCT01734707). The primary outcome was the rate of atherosclerosis pro- gression, measured by high-resolution B-mode ultrasonography as the increase in carotid intima-media thickness (CIMT) of the far wall of common carotid arteries [54].

At the baseline, blood serum taken from patients induced 1.56-fold increase in intracellular cholesterol retentio in cell culture test. In the placebo group, the mean value of serum induced intracellular cholesterol retention did not change significantly during two years. On the opposite, in Allicor-treated patients the mean level of intracellular cholesterol retention was significantly lowered already after first 3 months of treatment, and this effect was maintained during the study. We found statistically significant difference in the dynamic of changes in intracellular cholesterol retention between Allicor-treated and placebo groups. Allicor significantly reduced CIMT compared to baseline and the placebo group, while spontaneous atherosclerosis progression prevailed in the placebo group.

Our data are generally consistent with the results of a double-blinded, placebo-controlled randomized study by Koscielny et al. [55]. That study has been demonstrated that 4-year treatment with the garlic-based drug Kwai inhibited the increase in volume of atherosclerotic plaques in carotid and femoral arteries by $5 \%-18 \%$.

Atherosclerosis regression effect of Allicor revealed in the AMAR study is comparable with the results of most successful trials with other compounds [56-63]. Those studies employed potent lipid-lowering agents or calcium antagonists, whose beneficial effects of treatment were attributed to reduction in LDL cholesterol, the major risk factor for atherosclerosis development, or arterial wall stress.

Effects of Allicor promoted new clinical trials of two other drugs based on natural products, Inflaminat, which possesses anti-cytokine activity, and the phytoestrogenrich drug Karinat, which is designed for postmenopausal women.

Inflammatory cytokines play significant role at every stage of atherogenesis [64-66]. So, anti-cytokine drugs may be effective for the prevention of atherosclerosis. We have developed drug Inflaminat, which is based on calendula, elder and violet. Our laboratory investigations demonstrated that Inflaminat suppresses secretion of proinflammatory cytokines and reduces intracellular cholesterol retention. We have carried out a pilot study (ClinicalTrials.gov Identifier, NCT01743404) with Inflaminat using a protocol similar to that of the AMAR study. New study demonstrated atherosclerosis regression effects of Inflaminat and a statistically significant difference from the baseline as well as from placebo group in asymptomatic men [54].

The effective approaches to atherosclerosis prevention in postmenopausal women do not exist. Hormone re- 
placement therapy is not acceptable due to the negative results of clinical studies, including WHI, PEPI, and HERS [67-73]. Phytoestrogens may be an alternative to hormone replacement therapy, but practically nothing is known about their effects on atherosclerosis.

We selected phytoestrogen-rich botanicals on the basis of their ability to prevent intracellular cholesterol retention in ex vivo test system. The following combination was chosen: garlic powder, extract of grape seeds, green tea leaves, and hop cones, all of them produced significant anti-atherogenic effects. This combination was used for development of novel isoflavonoid-rich dietary supplement Karinat. Karinat prevents intracellular cholesterol retention and is characterized by good phytoestrogen profile, providing additional amounts of biologically active polyphenols, including resveratrol, genisteine, and daidzeine. Moreover Karinat contains additional amounts of $\beta$-carotene, $\alpha$-tocopherol and ascorbic acid to provide the necessary daily intake of antioxidants.

We have carried out a randomized, double-blinded, placebo-controlled pilot clinical trial to reveal possible atherosclerosis-related effects of Karinat in healthy postmenopausal women (ClinicalTrials.gov Identifiers, NCT01741974 and NCT01742000). The annual rate of changes in CIMT was monitored. In the Karinat group the average CIMT was not changed (statistically insignificant increase of $6 \mu \mathrm{m}$ per year, less than $1 \%$ ). The progression of existing plaques was slower by $32 \%$ per year. Thus, the use of Karinat in postmenopausal women almost completely suppresses the formation of new atherosclerotic lesions, and it slows the progression of existing lesions [54].

\section{CONCLUSIONS}

Our basic studies have demonstrated that intracellular cholesterol retention is the key initiating process in atherogenesis. On the basis of our data, we have developed cellular models and an approach to prevent intracellular cholesterol retention. We have demonstrated that prevention of intracellular cholesterol retention leads to the prevention of atherosclerosis progression and/or its regression in patients. We can conclude that our basic findings are successfully translated into clinics.

Unfortunately, natural products with anti-atherosclerotic therapeutic potential are not prescribed by medical practitioners as anti-atherosclerotic agents. However, our data allow us to consider botanicals as anti-atherosclerotic prescriptions [74].

\section{ACKNOWLEDGEMENTS}

This work was supported by the Russian Ministry of Education and
Science.

\section{REFERENCES}

[1] Williams, K.J. and Tabas, I. (1995) The Response-toretention hypothesis of early atherogenesis. Arteriosclerosis, Thrombosis, and Vascular Biology, 15, 551-561. doi:10.1161/01.ATV.15.5.551

[2] Williams, K.J. and Tabas, I. (1998) The response-to-retention hypothesis of atherogenesis reinforced. Current Opinion in Lipidology, 9, 471-474. doi:10.1097/00041433-199810000-00012

[3] Tabas, I., Williams, K.J. and Borén, J. (2007) Subendothelial lipoprotein retention as the initiating process in atherosclerosis: Update and therapeutic implications. Circulation, 116, 1832-1844. doi:10.1161/CIRCULATIONAHA.106.676890

[4] Insull Jr., W. (2009) The pathology of atherosclerosis: Plaque development and plaque responses to medical treatment. The American Journal of Medicine, 122, S3S14. doi:10.1016/j.amjmed.2008.10.013

[5] Moore, K.J. and Freeman, M.W. (2008) Targeting innate immunity for CV benefit. Drug Discovery Today Therapeutic Strategies, 5, 15-23. doi:10.1016/j.ddstr.2008.05.007

[6] Orekhov, A.N., Tertov, V.V., Kudryashov, S.A. and Smirnov, V.N. (1990) Triggerlike stimulation of cholesterol accumulation and DNA and extracellular matrix synthesis induced by atherogenic serum or low density lipoprotein in cultured cells. Circulation Research, 66, 311-320. doi:10.1161/01.RES.66.2.311

[7] Orekhov, A.N., Tertov, V.V., Pokrovsky, S.N., Iyu, A., Martsenyuk, O.N., Lyakishev, A.A. and Smirnov, V.N. (1988) Blood serum atherogenicity associated with coronary atherosclerosis. evidence for nonlipid factor providing atherogenicity of low-density lipoproteins and an approach to its elimination. Circulation Research, 62, 421429. doi:10.1161/01.RES.62.3.421

[8] Kruth, H.S. (2011) Receptor-independent fluid-phase pinocytosis mechanisms for induction of foam cell formation with native low-density lipoprotein particles. Current Opinion in Lipidology, 22, 386-393. doi:10.1097/MOL.0b013e32834adadb

[9] Yuan, Y., Li, P. and Ye, J. (2012) Lipid homeostasis and the formation of macrophage-derived foam cells in atherosclerosis. Protein \& Cell, 3, 173-181. doi:10.1007/s13238-012-2025-6

[10] Orekhov, A.N., Tertov, V.V., Mukhin, D.N. and Mikhailenko, I.A. (1989) Modification of low density lipoprotein by desialylation causes lipid accumulation in cultured cells. Discovery of desialylated lipoprotein with altered cellular metabolism in the blood of atherosclerotic patients. Biochemical and Biophysical Research Communications, 162, 206-211. doi:10.1016/0006-291X(89)91982-7

[11] Orekhov, A.N., Tertov, V.V. and Mukhin, D.N. (1991) Desialylated low density lipoprotein-Naturally occurring modified lipoprotein with atherogenic potency. Athero- 
sclerosis, 86, 153-161. doi:10.1016/0021-9150(91)90211-K

[12] Tertov, V.V., Sobenin, I.A., Gabbasov, Z.A., Popov, E.G. and Orekhov, A.N. (1989) Lipoprotein aggregation as an essential condition of intracellular lipid accumulation caused by modified low density lipoproteins. Biochemical and Biophysical Research Communications, 163, 489-494. doi:10.1016/0006-291X(89)92163-3

[13] Tertov, V.V., Sobenin, I.A., Tonevitsky, A.G., Orekhov, A.N. and Smirnov, V.N. (1990) Isolation of atherogenic modified (desialylated) low density lipoprotein from blood of atherosclerotic patients: Separation from native lipoprotein by affinity chromatography. Biochemical and Biophysical Research Communications, 167, 1122-1127. doi:10.1016/0006-291X(90)90639-5

[14] Tertov, V.V., Sobenin, I.A., Orekhov, A.N., Jaakkola, O., Solakivi, T. and Nikkari, T. (1996) Characteristics of low density lipoprotein isolated from circulating immune complexes. Atherosclerosis, 122, 191-199. doi:10.1016/0021-9150(95)05737-4

[15] Tertov, V.V., Kaplun, V.V., Sobenin, I.A., Boytsova, E.Y., Bovin, N.V. and Orekhov, A.N. (2001) Human plasma trans-sialidase causes atherogenic modification of low density lipoprotein. Atherosclerosis, 159, 103-115. doi:10.1016/S0021-9150(01)00498-1

[16] Avogaro, P., Bittolo-Bon, G. and Cazzolato, G. (1988) Presence of a modified low density lipoprotein in humans. Arteriosclerosis, 8, 79-87. doi:10.1161/01.ATV.8.1.79

[17] Krauss R.M. and Burke, D.J. (1982) Identification of multiple subclasses of plasma low density lipoproteins in normal humans. Journal of Lipid Research, 23, 97-104.

[18] Tertov, V.V., Bittolo-Bon, G., Sobenin, I.A., Cazzolato, G., Orekhov, A.N. and Avogaro, P. (1995) Naturally occurring modified low density lipoproteins are similar if not identical: More electronegative and desialylated lipoprotein subfractions. Experimental and Molecular Pathology, 62, 166-172. doi:10.1006/exmp.1995.1018

[19] Tertov, V.V., Sobenin, I.A. and Orekhov, A.N. (1996) Similarity between naturally occurring modified desialylated, electronegative and aortic low density lipoprotein. Free Radical Research, 25, 313-319. doi:10.3109/10715769609149054

[20] La Belle, M. and Krauss, R.M. (1990) Differences in carbohydrate content of low density lipoproteins associated with low density lipoprotein subclass patterns. Journal of Lipid Research, 31, 1577-1588.

[21] Kirk, J.K., Davis, S.W., Hildebrandt, C.A., Strachan, E.N., Peechara, M.L. and Lord, R. (2011) Characteristics associated with glycemic control among family medicine patients with type 2 diabetes. North Carolina Medical Journal, 72, 345-350.

[22] Orekhov, A.N., Tertov, V.V., Kabakov, A.E., Iyu, A., Pokrovsky, S.N. and Smirnov, V.N. (1991) Autoantibodies against modified low density lipoprotein. nonlipid factor of blood plasma that stimulates foam cell formation. Arteriosclerosis and Thrombosis, 11, 316-326. doi:10.1161/01.ATV.11.2.316

[23] Orekhov, A.N. and Tertov, V.V. (1991) Atherogenicity of autoantibodies against low density lipoprotein. Agents and Actions, 32, 128-129. doi:10.1007/BF01983338

[24] Lopes-Virella, M.F. and Virella, G. (2010) Clinical significance of the humoral immune response to modified LDL. Clinical Immunology, 134, 55-65. doi:10.1016/j.clim.2009.04.001

[25] Tertov, V.V., Orekhov, A.N., Sayadyan, K.S., Serebrennikov, S.G., Kacharava, A.G., Lyakishev, A.A. and Smirnov, V.N. (1990) Correlation between cholesterol content in circulating immune complexes and atherogenic properties of CHD patients' serum manifested in cell culture. Atherosclerosis, 81, 183-189. doi:10.1016/0021-9150(90)90065-Q

[26] Kacharava, A.G., Tertov, V.V. and Orekhov, A.N. (1993) Autoantibodies against low-density lipoprotein and atherogenic potential of blood. Annals of Medicine, 25, 551555 .

[27] Tertov, V.V., Orekhov, A.N., Kacharava, A.G., Sobenin, I.A., Perova, N.V. and Smirnov, V.N. (1990) Low density lipoprotein-containing circulating immune complexes and coronary atherosclerosis. Experimental and Molecular Pathology, 52, 300-308.

doi:10.1016/0014-4800(90)90071-K

[28] Orekhov, A.N., Kalenich, O.S., Tertov, V.V. and Novikov, I.D. (1991) Lipoprotein immune complexes as markers of atherosclerosis. International Journal of Tissue Reactions, 13, 233-236.

[29] Orekhov, A.N., Kalenich, O.S., Tertov, V.V., Perova, N.V., Novikov, I.D., Lyakishev, A.A., Deev, A.D. and Ruda, M.Y. (1995) Diagnostic value of immune cholesterol as a marker for atherosclerosis. Journal of Cardiovascular Risk, 2, 459-466. doi:10.1097/00043798-199510000-00011

[30] Sobenin, I.A., Karagodin, V.P., Melnichenko, A.A., Bobryshev, Y.V. and Orekhov, A.N. (2013) Diagnostic and prognostic value of low density lipoprotein-containing circulating immune complexes in atherosclerosis. Journal of Clinical Immunology, 33, 489-495. doi:10.1007/s10875-012-9819-4

[31] Sobenin, I.A., Orekhova, V.A., Melnichenko, A., Bobryshev, Y.V. and Orekhov, A.N. (2012) Low density lipoprotein-containing circulating immune complexes have better prognostic value in carotid intima-media thickness progression than other lipid parameters. International Journal of Cardiology, 163, 747-748. doi:10.1016/j.ijcard.2012.09.175

[32] Orekhov, A.N., Tertov, V.V., Mukhin, D.N., Koteliansky, V.E., Glukhova, M.A., Frid, M.G., Sukhova, G.K., Khashimov, K.A. and Smirnov, V.N. (1989) Insolubilization of low density lipoprotein induces cholesterol accumulation in cultured subendothelial cells of human aorta. Atherosclerosis, 79, 59-70. doi:10.1016/0021-9150(89)90034-8

[33] Glukhova, M.A., Kabakov, A.E., Frid, M.G., Ornatsky, O.I., Belkin, A.M., Mukhin, D.N., Orekhov, A.N., Koteliansky, V.E. and Smirnov, V.N. (1988) Modulation of human aorta smooth muscle cell phenotype: A study of muscle-specific variants of vinculin, caldesmon, and actin expression. Proceedings of the National Academy of Sci- 
ences of the United States of America, 85, 9542-9546. doi:10.1073/pnas.85.24.9542

[34] Orekhov, A.N., Tertov, V.V., Mukhin, D.N., Koteliansky, V.E., Glukhova, M.A., Khashimov, K.A. and Smirnov, V.N. (1987) Association of low-density lipoprotein with particulate connective tissue matrix components enhances cholesterol accumulation in cultured subendothelial cells of human aorta. Biochimica et Biophysica Acta, 928, 251258. doi:10.1016/0167-4889(87)90183-2

[35] Melnichenko, A.A., Aksenov, D.V., Myasoedova, V.A., Panasenko, O.M., Yaroslavov, A.A., Sobenin, I.A., Bobryshev, Y.V. and Orekhov, A.N. (2012) Pluronic block copolymers inhibit low density lipoprotein self-association. Lipids, 47, 995-1000. doi:10.1007/s11745-012-3699-5

[36] Tertov, V.V., Orekhov, A.N., Sobenin, I.A., Gabbasov, Z.A., Popov, E.G., Yaroslavov, A.A. and Smirnov, V.N. (1992) Three types of naturally occurring modified lipoproteins induce intracellular lipid accumulation due to lipoprotein aggregation. Circulation Research, 71, 218228. doi:10.1161/01.RES.71.1.218

[37] Rekhter, M.D., Andreeva, E.R., Mironov, A.A. and Orekhov, A.N. (1991) Three-dimensional cytoarchitecture of normal and atherosclerotic intima of human aorta. American Journal of Pathology, 138, 569-580.

[38] Orekhov, A.N., Andreeva, E.R., Krushinsky, A.V. and Smirnov, V.N. (1984) Primary cultures of enzyme-isolated cells from normal and atherosclerotic human aorta. Medical Biology, 62, 255-259.

[39] Orekhov, A.N., Tertov, V.V., Novikov, I.D., Krushinsky, A.V., Andreeva, E.R., Lankin V.Z. and Smirnov, V.N. (1985) Lipids in cells of atherosclerotic and uninvolved human aorta: I. lipid composition of aortic tissue and enzyme isolated and cultured cells. Experimental and Molecular Pathology, 42, 117-137. doi:10.1016/0014-4800(85)90022-X

[40] Orekhov, A.N., Krushinsky, A.V., Andreeva, E.R., Repin V.S. and Smirnov, V.N. (1986) Adult human aortic cells in primary culture: Heterogeneity in shape. Heart and Vessels, 2, 193-201. doi:10.1007/BF02059968

[41] Yamada, S., Guo, X., Yoshizawa, M., Li, Z., Matsuyama, A., Hashimoto, H. and Sasaguri, Y. (2011) Primary desmoplastic cutaneous leiomyosarcoma associated with high MIB-1 labeling index: A teaching case giving rise to diagnostic difficulties on a small biopsy specimen. $P a$ thology, Research and Practice, 207, 728-732. doi:10.1016/j.prp.2011.08.008

[42] Orekhov, A.N., Kosykh, V.A., Repin, V.S. and Smirnov, V.N. (1983) Cell proliferation in normal and atherosclerotic human aorta. II. Autoradiographic observation on deoxyribonucleic acid synthesis in primary cell culture. Laboratory Investigation, 48, 749-754.

[43] Orekhov, A.N., Tertov, V.V., Kudryashov, S.A., Khashimov, Kh.A. and Smirnov, V.N. (1986) Primary culture of human aortic intima cells as a model for testing anti-atherosclerotic drugs. Effects of cyclic AMP, prostaglandins, calcium antagonists, antioxidants, and lipid-lowering agents. Atherosclerosis, 60, 101-110. doi:10.1016/0021-9150(86)90002-X
[44] Chazov, E.I., Tertov, V.V., Orekhov, A.N., Lyakishev, A.A., Perova, N.V., Kurdanov, Kh.A., Khashimov, Kh.A., Novikov, I.D. and Smirnov, V.N. (1986) Atherogenicity of blood serum from patients with coronary heart disease. Lancet, 2, 595-598. doi:10.1016/S0140-6736(86)92426-8

[45] Tertov, V.V., Orekhov, A.N., Ryong, Li.Hwa. and Smirnov, V.N. (1988) Intracellular cholesterol accumulation is accompanied by enhanced proliferative activity of human aortic intimal cells. Tissue \& Cell, 20, 849-854. doi:10.1016/0040-8166(88)90026-2

[46] Tertov, V.V., Orekhov, A.N., Martsenyuk, O.N., Perova, N.V. and Smirnov, V.N. (1989) Low density lipoproteins isolated from the blood of patients with coronary heart disease induce the accumulation of lipids in human aortic cells. Experimental and Molecular Pathology, 50, 337347. doi:10.1016/0014-4800(89)90043-9

[47] Orekhov, A.N. (1990) In vitro models of antiatherosclerotic effects of cardiovascular drugs. The American Journal of Cardiology, 66, 23I-28I. doi:10.1016/0002-9149(90)91260-D

[48] Palatini, P. (2009) Elevated heart rate in cardiovascular diseases: A target for treatment? Progress in Cardiovascular Diseases, 52, 46-60. doi:10.1016/j.pcad.2009.05.005

[49] Schulman, I.H., Zachariah, M. and Raij, L. (2005) Calcium channel blockers, endothelial dysfunction, and combination therapy. Aging Clinical and Experimental Research, 17, 40-45.

[50] Orekhov, A.N., Baldenkov, G.N., Tertov, V.V., Ryong, Li.Hwa., Kozlov, S.G., Lyakishev, A.A., Tkachuk, V.A., Ruda, M.Ya. and Smirnov, V.N. (1988) Cardiovascular drugs and atherosclerosis: Effects of calcium antagonists, beta-blockers, and nitrates on atherosclerotic characteristics of human aortic cells. Journal of Cardiovascular Pharmacology, 12, S66-S68. doi:10.1097/00005344-198812006-00017

[51] Loaldi, A., Polese, A., Montorsi, P., Cesare, N.De., Fabbiocchi, F., Ravagnani, P. and Guazzi, M.D. (1989) Comparison of nifedipine, propranolol and isosorbide dinitrate on angiographic progression and regression of coronary arterial narrowings in angina pectoris. The American Journal of Cardiology, 64, 433-439. doi:10.1016/0002-9149(89)90417-7

[52] Orekhov, A.N., Baldenkov, G.N., Tertov, V.V., Ruda, M.Ya., Khashimov, Kh.A., Kudryashov, S.A., Li, H.R., Kozlov, S.G., Lyakishev, A.A., Tkachuk V.A. and Smirnov, V.N. (1990) Antiatherosclerotic effects of calcium antagonists. Study in human aortic cell culture. Herz, 15, 139-145.

[53] Orekhov, A.N. and Tertov, V.V. (1997) In vitro effect of garlic powder extract on lipid content in normal and atherosclerotic human aortic cells. Lipids, 32, 1055-1060. doi:10.1007/s11745-997-0136-7

[54] Orekhov, A.N. and Grünwald, J. (1997) Effects of garlic on atherosclerosis. Nutrition, 13, 656-663. doi:10.1016/S0899-9007(97)83010-9

[55] Orekhov, A.N., Sobenin, I.A., Korneev, N.V., Kirichenko, T.V., Myasoedova, V.A., Melnichenko, A.A., Balcells, M., Edelman, E.R. and Bobryshev, Y.V. (2012) Anti-athero- 
sclerotic therapy based on botanicals. Recent Patents on Cardiovascular Drug Discovery.

[56] Koscielny, J., Klüssendorf, D., Latza, R., Schmitt, R., Radtke, H., Siegel, G. and Kiesewetter, H. (1999) The antiatherosclerotic effect of Allium sativum. Atherosclerosis, 144, 237-249. doi:10.1016/S0021-9150(99)00060-X

[57] Crouse 3rd, J.R., Byington, R.P., Bond, M.G., Espeland, M.A., Craven, T.E., Sprinkle, J.W., McGovern, M.E. and Furberg, C.D. (1995) Pravastatin, lipids, and atherosclerosis in the carotid arteries (PLAC-II). American Journal of Cardiology, 75, 455-459. doi:10.1016/S0002-9149(99)80580-3

[58] Salonen, R., Nyyssonen, K., Porkkala, E., Rummukainen, J., Belder, R., Park, J.S. and Salonen, J.T. (1995) Kuopio atherosclerosis prevention study (KAPS). A populationbased primary preventive trial of the effect of LDL lowering on atherosclerotic progression in carotid and femoral arteries. Circulation, 92, 1758-1764. doi:10.1161/01.CIR.92.7.1758

[59] Smilde, T.J., van Wissen, S., Wollersheim, H., Trip, M.D., Kastelein, J. and Stalenhoef, A.F. (2001) Effect of aggressive versus conventional lipid lowering on atherosclerosis progression in familial hypercholesterolaemia (ASAP): A prospective, randomised, double-blind trial. Lancet, 357, 577-581. doi:10.1016/S0140-6736(00)04053-8

[60] Pitt, B., Byington, R.P., Furberg, C.D., Hunninghake, D.B., Mancini, G.B., Miller, M.E. and Riley, W. (2000) Effect of amlodipine on the progression of atherosclerosis and the occurrence of clinical events. Prevent investigators. Circulation, 102, 1503-1510. doi:10.1161/01.CIR.102.13.1503

[61] Blankenhorn, D.H., Selzer, R.H., Crawford, D.W., Barth, J.D., Liu, C.R., Liu, C.H., Mack W.J. and Alaupovic, P. (1993) Beneficial effects of colestipol-niacin therapy on the common carotid artery. Two- and four-year reduction of intima-media thickness Measured by ultrasound. Circulation, 88, 20-28. doi:10.1161/01.CIR.88.1.20

[62] Hodis, H.N. (1995) Reversibility of atherosclerosis-evolving perspectives from two arterial imaging clinical trials: The cholesterol lowering atherosclerosis regression study and the monitored atherosclerosis regression study. Journal of Cardiovascular Pharmacology, 25, S25-S31.

[63] Blankenhorn, D.H., Azen, S.P., Kramsch, D.M., Mack, W.J., Cashin-Hemphill, L., Hodis, H.N., DeBoer, L.W., Mahrer, P.R., Masteller, M.J., Vailas, L.I., Alaupovic, P., Hirsch L.J., MARS Research Group (1993) Coronary angiographic changes with lovastatin therapy. The monitored atherosclerosis regression study (MARS). Annals of Internal Medicine, 119, 969-976. doi:10.7326/0003-4819-119-10-199311150-00002

[64] Zanchetti, A., Rosei, E.A., Dal Palù, C., Leonetti, G., Magnani, B. and Pessina, A. (1998) The verapamil in hypertension and atherosclerosis study (VHAS): Results of long-term randomized treatment with either verapamil or chlorthalidone on carotid intima-media thickness. Journal of Hypertension, 16, 1667-1676. doi:10.1097/00004872-199816110-00014

[65] Libby, P. (2006) Inflammation and cardiovascular disease mechanisms. The American Journal of Clinical Nutrition, 83, 456S-460S.

[66] Aidinian, G., Weiswasser, J.M. and Arora, S. (2006) Carotid plaque morphologic characteristics. Perspectives in Vascular Surgery and Endovascular Therapy, 18, 63-70. doi:10.1177/153100350601800124

[67] Daugherty, A., Webb, N.R., Rateri, D.L. and King, V.L. (2005) The immune system and atherogenesis. Cytokine regulation of macrophage functions in atherogenesis. Journal of Lipid Research, 46, 1812-1822. doi:10.1194/jlr.R500009-JLR200

[68] Burger, H.G., Maclennan, A.H., Huang, K.E. and Castelo-Branco, C. (2012) Evidence-based assessment of the impact of the WHI on women's health. Climacteric, 15, 281-287. doi:10.3109/13697137.2012.655564

[69] de Villiers, T.J. and Stevenson, J.C. (2012) The WHI: The effect of hormone replacement therapy on fracture prevention. Climacteric, 15, 263-266. doi:10.3109/13697137.2012.659975

[70] Ellis, M.J., Suman, V.J., Hoog, J., Lin, L., Snider, J., Prat, A., Parker, J.S., Luo, J., DeSchryver, K., Allred, D.C., Esserman, L.J., Unzeitig, G.W., Margenthaler, J., Babiera, G.V., Marcom, P.K., Guenther, J.M., Watson, M.A., Leitch, M., Hunt, K. and Olson, J.A. (2011) Randomized phase II neoadjuvant comparison between letrozole, anastrozole, and exemestane for postmenopausal women with estrogen receptor-rich stage 2 to 3 breast cancer: Clinical and biomarker outcomes and predictive value of the baseline pam50-based intrinsic subtype-ACOSOG Z1031. Journal of Clinical Oncology, 29, 2342-2349. doi:10.1200/JCO.2010.31.6950

[71] Smith, N.L., Wiley, J.R., Legault, C., Rice, K.M., Heckbert, S.R., Psaty, B.M., Tracy, R.P. and Cushman, M. (2008) Effect of progestogen and progestogen type on hemostasis measures in postmenopausal women: The postmenopausal estrogen/progestin intervention (pepi) study. Menopause, 15, 1145-1150. doi:10.1097/gme.0b013e3181775eca

[72] Masood, D.E., Roach, E.C., Beauregard, K.G. and Khalil, R.A. (2010) Impact of sex hormone metabolism on the vascular effects of menopausal hormone therapy in cardiovascular disease. Current Drug Metabolism, 11, 693714. doi:10.2174/138920010794233477

[73] Pellegrini, C.N., Vittinghoff, E., Lin, F., Hulley, S.B. and Marcus, G.M. (2009) Statin use is associated with lower risk of atrial fibrillation in women with coronary disease: The HERS trial. Heart, 95, 704-708. doi:10.1136/hrt.2008.154054

[74] Slevin, M., Ahmed, N., Wang, Q., McDowell, G. and Badimon, L. (2012) Unique vascular protective properties of natural products: Supplements or future main-line drugs with significant anti-atherosclerotic potential?. Vascular Cell, 4, 9. doi:10.1186/2045-824X-4-9 